Pacific Journal of Mathematic 


\title{
A NOTE ON THE MINIMALITY OF CERTAIN BITRANSFORMATION GROUPS
}

\author{
TA-SuN Wu
}

Let $(T, X)$ be a transformation group with compact Hausdorff space $X$ and topological group $T$. Let $(X, G)$ be a transformation group with $G$ a compact topological group. Then the triple $(T, X, G)$ is a bitransformation group if $(t x) g=t(x g)$ for all $t \in T, x \in X, g \in G$ and the action of $G$ on $X$ is strongly effective, (that is $x g=x$ if and only if $g=$ the identity element $e$ of $G$ ). A bitransformation group $(T, X, G)$, induces canonically the transformation group $(T, X / G)$ where $X / G$ is the orbit space of $(X, G)$. Let $(T, X, G)$ be a bitransformation group. Suppose $(T, X / G)$ is a minimal transformation group whereas $(T, X)$ is not a minimal transformation group then what is the possible structure of $(T, X, G)$ ?

In this note, it is proved that the fundamental group of $X$ must be of certain form when $G$ is a circle group. Use this result together with some results of Malcev, a necessary and sufficient condition is found for the minimality of certain nilflows.

THEOREM 1. Let $(T, X, G)$ be a bitransformation group with circle group $G$. If $(T, X / G)$ is a minimal transformation group and $(T, X)$ is not minimal, then there exists a finite group $H$ of $G$ such that $X$ is a covering space of $X / H$ and $X / H$ admits a section over $X / G$.

Proof. Let $M$ be a minimal set in $(T, X)$. Let $H=\{g \in G$ : $g M=M\}$. Then $H$ is a proper closed subgroup of $G$. Thus $H$ is a finite group. The natural projection $p: X / H \rightarrow X / G$ is a principal bundle map with fiber $G / H$. Then $p \mid M / H: M / H \rightarrow X / G$ is a homeomorphism. Thus $p$ admits a global cross section.

COROLlary. Besides all the notation of Theorem 1, assume that $X$ is path connected. Then $\pi(X)$ is a isomorphic with a subgroup of $\pi(X / G) \cdot Z$, where $Z$ is the integer group and the dot denotes semidirect product.

From now on, we shall assume that $N$ is a simply connected nilpotent analytic group. A subgroup $H$ of $N$ is a uniform subgroup if the homogeneous space $N / H$ is compact. Let $\Gamma$ be a discrete uniform subgroup of $N$. Then $\Gamma$ is torsion-free and finitely generated [2]. For each discrete uniform subgroup $\Gamma$ of $N$, there is a subset 
$D=\left\{d_{1}, \cdots, d_{m}\right\}$ of $\Gamma$ with the following properties:

(1) there exist $m$ one-parameter groups $d_{i}(t)$ such that $N=$ $\left\{d_{1}\left(t_{1}\right) d_{2}\left(t_{2}\right) \cdots d_{m}\left(t_{m}\right): t_{1}, \cdots, t_{m} \in R\right.$, reals $\}$.

(2) $\Gamma=\left\{d_{1}\left(n_{1}\right) d_{2}\left(n_{2}\right) \cdots d_{m}\left(n_{m}\right): n_{1}, n_{2}, \cdots, n_{m} \in Z\right.$, integers $\}$.

(3) If $N_{i}=\left\{d_{i}\left(t_{i}\right) \cdots d_{m}\left(t_{m}\right): t_{i}, t_{i+1}, \cdots, t_{m}\right.$ any real numbers, then $N_{i}$ is a closed subgroup of $N$ and $N_{i}$ is normal in $N_{i-1} \cdot \quad D$ is called a canonical basis of $\Gamma$.

Let $F$ be a nilpotent group and $F=F^{0} \supset F^{1} \supset F^{2} \supset \cdots \supset F^{p} \supset F^{p+1}=(e)$ be the descending central series. We recall that $F^{i}=\left[F, F^{i-1}\right]$, where $\left[F, F^{i-1}\right]$ is the subgroup of $F$ generated by $\left\{[a, b]=a b a^{-1} b^{-1}\right.$ : $a \in F, b \in F^{i-1}$. Let $N=N^{0} \supset N^{1} \supset \cdots \supset N^{m} \supset N^{m+1}=(e)$ be the descending central series. Then $\Gamma^{p} \subset N^{p} \cap \Gamma \subset N^{p}$ we shall prove that.

Lemma 1. $\Gamma^{p}$ is uniform in $N^{p}$ and $\Gamma \cap N^{p} / \Gamma^{p}$ is finite.

Proof. Let $V$ be the vector subspace of $N^{p}$ spanned by $\Gamma^{p}$. Let $D=\left\{d_{1}, \cdots, d_{l}, \cdots, d_{k}, \cdots, d_{m}\right\}$ be a canonical basis of $D$ such that $\left\{d_{l}, \cdots, d_{m}\right\},\left\{d_{k}, \cdots, d_{m}\right\}$ are canonical basis for $N^{p-1}$ and $N^{p}$ respectively. Then $\left\{d_{i} d_{j}(t) d_{i}^{-1} d_{j}(t)^{-1}: t \in R\right\}$ is an one-parameter group containing $d_{i} d_{j} d_{i}^{-1} d_{j}^{-1}$ if $l \leqq j$. Hence $\left\{d_{i} d_{j}(t) d_{i}^{-1} d_{j}(t)\right\} \subseteq V$. For each fixed $t_{0} \in R,\left\{d_{i}(t) d_{j}\left(t_{0}\right) d_{i}(t)^{-1} d_{j}\left(t_{0}\right)^{-1}: t \in R\right\}$ is an one parameter group containing $d_{i} d_{j}\left(t_{0}\right) d_{i} d_{j}\left(t_{0}\right)^{-1} \in V$ if $l \leqq j$. This implies that $d_{i}(s) d_{j}(t) d_{i}(s)^{-1} d_{j}(t)^{-1} \in V$ for any $s, t \in R$. Thus $N^{p}=\left[N, N^{p-1}\right] \leqq V$ and $N^{p}=V$. Hence $\Gamma^{p}$ is uniform in $N^{p}$ and $\Gamma \cap N^{p} / \Gamma^{p}$ is finite.

In order to state our next result, we recall the definition of coset transformation group. Let $T$ be a topological group and $G / H$ a coset space. Let $O$ be a continuous homomorphism from $T$ into $G$. Then $(T, G / H)$ is a coset transformation group (relative to $O$ ) if $\operatorname{tg} H=$ $\mathcal{O}(t) g H$ for $t \in T, g \in G$.

Proposition 1. Let $(T, N / \Gamma)$ be a coset transformation group where $N$ is a simply connected nilpotent analytic group and $\Gamma$ is discrete uniform subgroup of $N$. Assume that $\operatorname{dim} N^{q} / N^{q H}=1$ for $q \geqq 1$. Then $(T, N / \Gamma)$ is minimal if and only if $\left(T, N / \Gamma N^{\prime}\right)$ is minimal.

Proof. We shall prove this theorem by induction based the length of nilpotency of $\Gamma$. When $\Gamma$ is abelian, there is nothing to prove. Assume $\left(T, N / \Gamma N^{\prime}\right)$ is minimal. By induction hypothesis $\left(T, N / N^{p} / \Gamma N^{p} / N^{p}\right)$ is minimal. Thus $\left(T, N / \Gamma N^{p}\right)$ is minimal. Let $H^{q}=\left\{d_{q}\left(t_{q}\right) \cdots d_{m}\left(t_{m}\right)\right.$ : $\left.t_{q}, \cdots t_{m} \in R\right\}$. Suppose $\left(T, N / \Gamma H^{q}\right)$ is minimal and $\left(T, N / \Gamma H^{q+1}\right)$ is not minimal. Then $\left(T, N / \Gamma H^{q+1}, \Gamma H^{q} / \Gamma H^{q+1}\right)$ is a bitransformation group. By Corollary $1, \Gamma / \Gamma \cap H^{q+1}$ is isomorphic with a subgroup of $\Gamma / \Gamma \cap H^{q} \times Z$. Then the image of $d_{q}\left(\Gamma \cap H^{q+1}\right)$ under this isomorphism 
must be of the form $(x, z)$ for some nonzero integer ${ }^{1}$. Thus $(x, z)^{\alpha} \notin$ $\left(\Gamma / \Gamma \cap H^{q}\right)$ if $\alpha$ is a nonzero integer. On the other hand, $\left[\left(\Gamma / \Gamma \cap H^{q} \times Z\right.\right.$, $\left.\left(\Gamma / \Gamma \cap H^{q}\right) \times Z\right] \subset \Gamma / \Gamma \cap H^{q}$. This fact together with Lemma 1 , we have the contradiction. Thus $\left(T, N / \Gamma H^{q+1}\right)$ is minimal. By finite induction, $(T, N / \Gamma)$ is minimal.

THEOREM 2. Let $(T, N / H)$ be a coset transformation with nilpotent analytic group $N$ and closed uniform subgroup $H$ such that $\operatorname{dim}\left(N / \Gamma H_{0}\right)^{q} /\left(N / \Gamma H_{0}\right)^{q+1}=1$. Then $(T, N / H)$ is minimal if and only if $(T, N / H[N, N])$ is minimal.

Proof. Let $H_{0}$ be the identity component of $H$. Then $H_{0}$ is a normal subgroup of $N$ and $N / H_{0}$ is simply connected. Let $\pi$ be the canonical projection from $N \rightarrow N / H_{0}$. Then $\pi^{-1}\left(\pi(\Gamma)\left[N / H_{0}, N / H_{0}\right]\right)=$ $H[N, N]$. Hence $H[N, N]$ is closed uniform subgroup of $N$. If $(T, N / H[N, N])$ is minimal, then $\left(T, N / H_{0} / H / H_{0}\right)$ is minimal by Proposition 1. But $(T, N / H)$ is isomorphic with $\left(T, N / H_{0} / H / H_{0}\right)$. Hence $(T, N / H)$ is minimal.

EXAMPLES. ([1, p. 52]) consider the group $G$ of all real matrices of the form

$$
\left(\begin{array}{lll}
1 & x & z \\
0 & 1 & y \\
0 & 0 & 1
\end{array}\right)
$$

and let $D$ be the uniform discrete subgroup of matrices

$$
\left(\begin{array}{lll}
1 & a & c \\
0 & 1 & b \\
0 & 0 & 1
\end{array}\right)
$$

for all integers $a, b, c$. Then $M=G / D$ is a nilmanifold. Consider a one-parameter subgroup $\varphi(t)$ of $G$ given by

$$
\operatorname{expt}\left(\begin{array}{ccc}
0 & \alpha & \gamma \\
0 & 0 & \beta \\
0 & 0 & 0
\end{array}\right)=\left(\begin{array}{lll}
1 & 2 t & \lambda t+\frac{1}{2} \alpha \beta t^{2} \\
0 & 1 & \beta t \\
0 & 0 & 1
\end{array}\right) .
$$

Take a point $Q \in M$ given by the coset

$$
\left(\begin{array}{ccc}
1 & x_{0} & z_{0} \\
0 & 1 & y_{0} \\
0 & 0 & 1
\end{array}\right) D
$$

\footnotetext{
${ }^{1}$ Since $\Gamma$ is nilpotent, the semi-direct product here is actually a direct product.
} 
the orbit $\varphi_{t}^{*}(t)$ in $M$ is

$$
\left(\begin{array}{ccc}
1 & t+x_{0} & \gamma t+\frac{\alpha \beta}{2} t^{2}+z_{0}+\alpha+y_{0} \\
0 & 1 & \beta t+y_{0} \\
0 & 0 & 1
\end{array}\right) D .
$$

Then $D[G, G]$ is the set of all the matrices

$$
\left(\begin{array}{lll}
1 & a & z \\
0 & 1 & b \\
0 & 0 & 1
\end{array}\right)
$$

for all integers $a, b$ and real number $z$. And $(\varphi(t), G / D[G, G])$ is isomorphic with the continuous flow on two-dimensional torus with the direction ratio $(\alpha, \beta)$.

By Theorem 2, $(\varphi(t), M)$ is minimal if and only if ( $\varphi(t), G / D[G, G])$. The latter is minimal if and only if $\alpha$ and $\beta$ are rationally independent. This answers the question in [1, p. 53].

Added in proof. After this note went in print, we have the proof of the following statement. Let $G$ be a simply connected solvable analytic group and $\Gamma$ be a nilpotent uniform subgroup of $G$. Then $(T, G / P)$ is minimal if and only if $(T, G / \Gamma N)$ is minimal, here $N$ denotes the analytic subgroup of $G$ which contains $[\Gamma, \Gamma]$ as a uniform subgroup. The proof uses a stronger form of Lemma 1 (replacing the circle group by torus groups) and the nilpotency of $\Gamma$. The detail will appear later.

\section{REFERENCES}

1. L. Auslander, etc., Flows on Homogeneous spaces, Ann. of Math. Studies, number 53, Princeton, New Jersey, 1963.

2. A. Malcev, On a class of homogeneous spaces, Trans. Amer. Math. Soc. 39 (1949).

Received April 15, 1969. Partially supported by NSF GP-7527 and NSF g-GP-8961.

Case Western Reserve University 


\section{PACIFIC JOURNAL OF MATHEMATICS}

\section{EDITORS}

H. SAMELson

Stanford University

Stanford, California 94305

R. R. PHelPS

University of Washington

Seattle, Washington 98105
J. Dugundu

Department of Mathematics

University of Southern Californle

Los Angeles, California 9.0007

RICHARD ARENS

University of California

Los Angeles, California 9.0024

\section{ASSOCIATE EDITORS}
E. F. BECKENBACH
B. H. NeumanN
F. WOLE
K. Yoshida

\section{SUPPORTING INSTITUTIONS}

UNIVERSITY OF BRITISH COLUMBIA

CALIFORNIA INSTITUTE OF TECHNOLOGY

UNIVERSITY OF CALIFORNIA

MONTANA STATE UNIVERSITY

UNIVERSITY OF NEVADA

NEW MEXICO STATE UNIVERSITY

OREGON STATE UNIVERSITY

UNIVERSITY OF OREGON

OSAKA UNIVERSITY

UNIVERSITY OF SOUTHERN CALIFORNIA

\author{
STANFORD UNIVERSITY \\ UNIVERSITY OF TOKYO \\ UNIVERSITY OF UTAH \\ WASHINGTON STATE UNIVERSITY \\ UNIVERSITY OF WASHINGTON \\ AMERICAN MATHEMATICAL SOCIETY \\ CHEVRON RESEARCH CORPORATION \\ NAVAL WEAPONS CENTER
}

The Supporting Institutions listed above contribute to the cost of publication of this Journal, but they are not owners or publishers and have no responsibility for its content or policies.

Mathematical papers intended for publication in the Pacific Journal of Mathematics should be in typed form or offset-reproduced, (not dittoed), double spaced with large margins. Underline Greek letters in red, German in green, and script in blue. The first paragraph or two must be capable of being used separately as a synopsis of the entire paper. The editorial "we" must not be used in the synopsis, and items of the bibliography should not be cited there unless absolutely necessary, in which case they must be identified by author and Journal, rather than by item number. Manuscripts, in duplicate if possible, may be sent to any one of the four editors. Please classify according to the scheme of Math. Rev. Index to Vol. 39. All other communications to the editors should be addressed to the managing editor, Richard Arens, University of California, Los Angeles, California, 90024.

50 reprints are provided free for each article; additional copies may be obtained at cost in multiples of 50 .

The Pacific Journal of Mathematics is published monthly. Effective with Volume 16 the price per volume (3 numbers) is $\$ 8.00$; single issues, $\$ 3.00$. Special price for current issues to individual faculty members of supporting institutions and to individual members of the American Mathematical Society: $\$ 4.00$ per volume; single issues $\$ 1.50$. Back numbers are available.

Subscriptions, orders for back numbers, and changes of address should be sent to Pacific Journal of Mathematics, 103 Highland Boulevard, Berkeley, California, 94708.

PUBLISHED BY PACIFIC JOURNAL OF MATHEMATICS, A NON-PROFIT CORPORATION

Printed at Kokusai Bunken Insatsusha (International Academic Printing Co., Ltd.), 7-17, Fujimi 2-chome, Chiyoda-ku, Tokyo, Japan. 


\section{Pacific Journal of Mathematics}

\section{Vol. 36, No. 2 December, 1971}

George E. Andrews, On a partition problem of H. L. Alder ............ 279

Thomas Craig Brown, An interesting combinatorial method in the theory of locally finite semigroups .......................... 285

Yuen-Kwok Chan, A constructive proof of Sard's theorem ............. 291

Charles Vernon Coffman, Spectral theory of monotone Hammerstein

operators...................................... 303

Edward Dewey Davis, Regular sequences and minimal bases .......... 323

Israel (Yitzchak) Nathan Herstein and Lance W. Small, Regular elements in

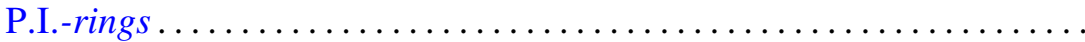

Marcel Herzog, Intersections of nilpotent Hall subgroups ..............

W. N. Hudson, Volterra transformations of the Wiener measure on the space

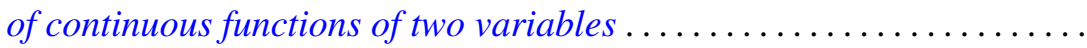

J. H. V. Hunt, An n-arc theorem for Peano spaces ................ 351

Arnold Joseph Insel, A decomposition theorem for topological group

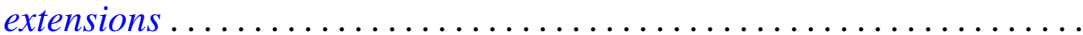

Caulton Lee Irwin, Inverting operators for singular boundary value

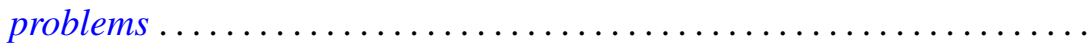

Abraham A. Klein, Matrix rings of finite degree of nilpotency ............ 387

Wei-Eihn Kuan, On the hyperplane section through a rational point of an algebraic variety...

John Hathway Lindsey, II, On a six-dimensional projective representation of $\mathrm{PSU}_{4}(3)$

Jorge Martinez, Approximation by archimedean lattice cones ...

J. F. McClendon, On stable fiber space obstructions .........

Mitsuru Nakai and Leo Sario, Behavior of Green lines at the Kuramochi boundary of a Riemann surface ....................

Donald Steven Passman, Linear identities in group rings. I. .

Donald Steven Passman, Linear identities in group rings. II ...

David S. Promislow, The Kakutani theorem for tensor products of

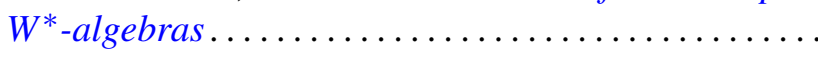

Richard Lewis Roth, On the conjugating representation of a finite group

Bert Alan Taylor, On weighted polynomial approximation of entire functions...

William Charles Waterhouse, Divisor classes in pseudo Galois

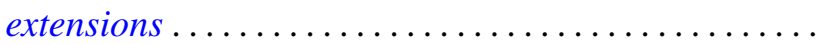

Chi Song Wong, Subadditive functions ...

Ta-Sun $\mathrm{Wu}$, A note on the minimality of certain bitransformation groups 